\title{
Comparative Study of Simple Choice Auditory Reaction Time of University Sports and Sedentary Female Students
}

\author{
Mohammad Nasim Reza, Shaybal Chanda \\ Department of Physical Education and Sports Science, Jashore University of Science and Technology, Jashore, Bangladesh
}

Email address:

nasimkhokon@yahoo.com (M. N. Reza), shaybalchanda@yahoo.com (S. Chanda)

\section{To cite this article:}

Mohammad Nasim Reza, Shaybal Chanda. Comparative Study of Simple Choice Auditory Reaction Time of University Sports and Sedentary Female Students. American Journal of Sports Science. Vol. 7, No. 4, 2019, pp. 155-158. doi: 10.11648/j.ajss.20190704.14

Received: September 19, 2019; Accepted: October 29, 2019; Published: November 5, 2019

\begin{abstract}
Simple choice auditory reaction time plays a vital role in daily life including sports. The balanced reaction of both sides of the human helps in achieving the highest movement output. The purpose of the study is to compare simple reaction time between university sports and sedentary female students based on preferred and non-preferred hand. Subjects were selected from Jashore University of Science and Technology, Bangladesh. They were bachelor and master students and were between 19-26 years old. There were 20 students in each group of sports and sedentary female students. Data was collected using the AVR machine. An average of 5 trials was calculated as the time score in millisecond. The result shows that in simple choice auditory reaction time of hands between sports and sedentary female students in the preferred hand, sport female mean $=18.25 \mathrm{~ms}$ and $\mathrm{SD}=2.07 \mathrm{~ms}$ and sedentary female students' mean $=20.45 \mathrm{~ms}$ and $\mathrm{SD}=1.67 \mathrm{~ms}$ with $\mathrm{t}_{(0.05)}(38)=-3.695$ and $\mathrm{p}$ $=0.001$. On the other hand, in the non-preferred hand Sport female mean $=20.20 \mathrm{~ms}$ and SD $=1.80 \mathrm{~ms}$, and Sedentary female mean $=21.70 \mathrm{~ms}$ and $\mathrm{SD}=0.98 \mathrm{~ms}$ with $\mathrm{t}_{(0.05)}(38)=-3.382$ and $\mathrm{p}=0.002$. Moreover, in the simple choice auditory reaction time between the preferred and non-preferred hand of sports and sedentary female players' preferred hand mean $=19.35 \mathrm{~ms}$ and $\mathrm{SD}=2.167 \mathrm{~ms}$, and non-preferred hand mean $=20.35 \mathrm{~ms}$ and $\mathrm{SD}=1.616 \mathrm{~ms}, \mathrm{t}_{(0.05)}(39)=-5.639$ and $\mathrm{p}=0.00$. So it is concluded that University sports female students are superior to sedentary female students in simple choice auditory reaction time in both the hands. Further, University female students' preferred hand is faster in simple choice auditory reaction time than that of non-preferred hand.
\end{abstract}

Keywords: Simple Choice Auditory Reaction Time, Preferred Hand, Non-Preferred Hand

\section{Introduction}

Reaction time is "the interval between stimulation and response" [1]. Collins dictionary [2] suggests that in psychology it is termed as "the lapse of time between stimulation and the beginning of the response." Deary [3] notated that since the middle of the nineteenth century reaction time has been a favorite topic of experimental psychologists. Michael [4] observedas the task became more complex Reactiontime lengthens accordingly. According to Dana [5], reactiontime increases with response complexity. Madanmohan reported that the decrease of reaction time indicates an enhancement in the information processing and reflexes [6]. Stimuli are of three types. Simple response reaction time: only one stimulus available in it and in its appearance one needs to respond. In the choice response reaction time: multiple numbers of stimuli are there and every stimulus needs a different response. Selection reaction time: there are different stimuli but only one needs to respond to one stimulus. Chandra confirmed that at rest, difference in reaction time is insignificant in preferred and non-preferred hands but it is significant while exercise was performed at elevated temperatures [7]. The simple auditory reaction time is one of the fastest reaction times; it is usually less than 100 $\mathrm{ms}$ and even neuromuscular-physiological components of simple auditory reaction times may reach less than $85 \mathrm{~ms}$ [8]. Chandra proposed that Visual reaction time is longer than auditory reaction time in all circumstances [7]. Shelton [9] noted that the mean auditory reaction time is approximately 284 milliseconds and faster than the visual reaction time; further, males have faster reaction times in comparison to females in both auditory and visual stimuli. Pancar [10] opined sedentary children exhibit faster reaction with increasing age between 11-18 years. Woods [11], Simple 
Reaction Time latencies increase in progression of age. In aerobic exercises as compared to non-exercisers irrespective of age and gender, auditory reaction time is better [12] Healthy adults had longer simplereactiontimes and made fewer correct choices under the influence of distracters compared to normal conditions [13].

The purpose of the study is to compare simple reaction time between university sports and sedentary female students based on preferred and non-preferred hand.

\section{Method}

\subsection{Selection of Subject}

Subjects were the student of Jashore University of Science and Technology, Bangladesh. Twenty sports female students and twenty sedentary female students were randomly selected and data were collected in the year 2019 at Human Performance Laboratory, Jashore University of Science and Technology, Bangladesh. All the students were undergraduate and postgraduate students. Subjects' age detail has shown in the table:

Table 1. Age of the Subjects.

\begin{tabular}{llllllll}
\hline \multicolumn{2}{l}{ Sports Female Students } & \multicolumn{5}{l}{ Sedentary Female Students } \\
\hline Min. (Year) & Max. (Year) & Mean. (Year. Month) & SD (Year) & Min. (Year) & Max. (Year) & Mean. (Year. Month) & SD (Year) \\
\hline 19 & 26 & 21.9 & 1.86 & 18 & 22 & 20.2 & 0.99 \\
\hline
\end{tabular}

\subsection{Equipment}

Two-Choice Audio-Visual Reaction (AVR) time Machine, MEDI System ISO 9001:2015 (QMS).

\subsection{Test Administration}

AVR machine was kept on the table and subjects were on the chair at sitting position. From a comfortable sitting position, students kept their index finger in contact with the AVR button to press after listening to the sound stimulus. The test administrator sat opposite side to the subject and kept his hand on the button of blowing sound with a screen of the AVR machine, and pushes the same button to create a sound of the same amplitude. Therefore, the subject could not realize when the administrator is going to blow the sound. Subjects were given detail instructions about the test and AVR machine function and cleared all doubts by the test administrator. Subjects hadthe opportunity of several trials to be familiarized with the AVR machine and test.

Students wereinstructed to press the button as so soon as possible after listening to the sound of the AVR machine. Laboratory was totally noise-free to have full concentration on the sound of AVR machine.

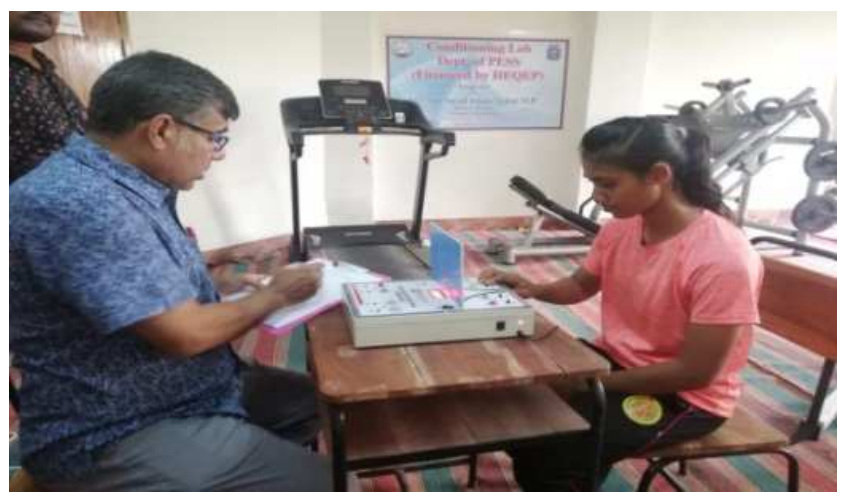

Figure 1. Sports Female Student Participating in Test.

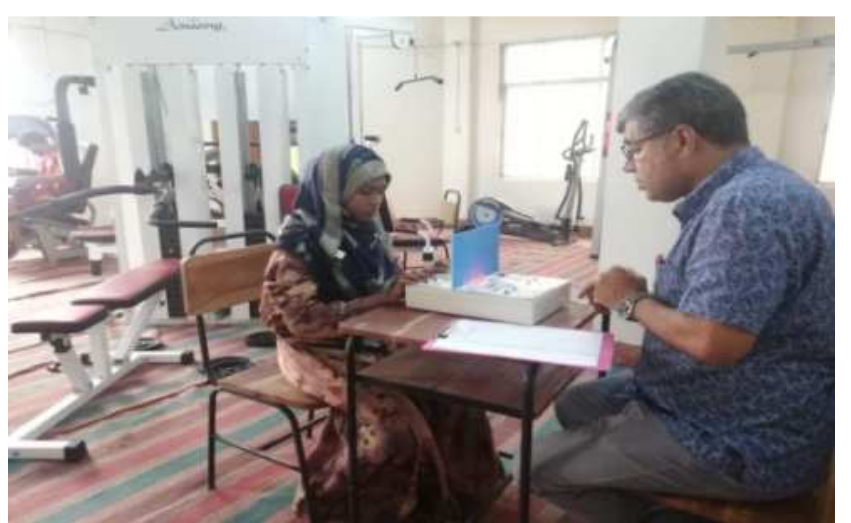

Figure 2. Sedentary Female Student Participating in Test.

\subsection{Data Collection Procedure}

Data was collected using both the hands' index fingers. First two digits of millisecond were considered for the study. All the students have given five trials of both the hands and the average score was calculated. This calculated average has accepted as individual data.

\subsection{Statistical Procedure}

Shapiro-Wilk test established that data were approximately normally distributed. Further, in the descriptive statisticsMean, SD, and in the inferential statistics- paired \& independent sample t-test were employed. The level of significance was set at $\mathrm{p} \leq 0.05$.

\subsection{Used Terms}

Preferred Hand: The hand, which one usually moves first without any specific intention and gets more strength compared to others.

Non-Preferred Hand: The hand, which one usually moves less without any specific intention and gets less strength compared to others. 


\section{Analysis of Data}

Table 2. Independent sample t-test of simple choice auditory reaction time of hands between sports and sedentary female students.

\begin{tabular}{|c|c|c|c|c|c|c|}
\hline \multirow{2}{*}{ Parameter } & & \multicolumn{2}{|l|}{ Descriptive } & \multicolumn{3}{|c|}{ Inferential: Independent Sample t-test } \\
\hline & & Mean (ms) & $S D(m s)$ & $t$ & $d f$ & Sig. (2-tailed) \\
\hline \multirow{2}{*}{ Preferred Hand } & Sports Female & 18.25 & 2.07 & \multirow{2}{*}{-3.695} & \multirow{2}{*}{38} & \multirow{2}{*}{.001} \\
\hline & Sedentary Female & 20.45 & 1.67 & & & \\
\hline Non-preferred Hand & $\begin{array}{l}\text { Sports Female } \\
\text { Sedentary Female }\end{array}$ & $\begin{array}{l}20.20 \\
21.70\end{array}$ & $\begin{array}{l}1.80 \\
0.98\end{array}$ & -3.282 & 38 & .002 \\
\hline
\end{tabular}

*Required value for being significant at $\alpha=0.05$ level of significance is $t(38)=2.024 \& p \leq 0.05$.

Table 3. Paired Sample t-test of simple choice auditory reaction time between the preferred and non-preferred hands of sports and sedentary female students.

\begin{tabular}{lllllll}
\hline \multirow{2}{*}{ Parameter } & & \multicolumn{4}{c}{ Inferential: Paired Sample t-test } \\
\cline { 2 - 7 } & & Mean $(\boldsymbol{m s})$ & $\boldsymbol{S D}(\boldsymbol{m s})$ & $\boldsymbol{t}$ & $\boldsymbol{d}$ S & Sig. (2-tailed) \\
\hline \multirow{2}{*}{ Pair 1 } & Preferred Hand & 19.35 & 2.167 & -5.639 & 39 & 0.00 \\
\hline
\end{tabular}

*Required value for being significant at $\alpha=0.05$ level of significance is t (39) $=2.023 \& p \leq 0.05$.

\section{Result}

Table: 2 of independent sample t-test of simple choice auditory reaction time of hands between sports and sedentary female students shows that in the preferred hand sport female mean $=18.25 \mathrm{~ms}$ and $\mathrm{SD}=2.07 \mathrm{~ms}$. On the other hand, sedentary female students' mean $=20.45 \mathrm{~ms}$ and $\mathrm{SD}=1.67$ ms with $\mathrm{t}_{(0.05)}(38)=-3.695$ and $\mathrm{p}=0.001$ is statistically significant. Whereas, in the non-preferred hand Sport female mean $=20.20 \mathrm{~ms}$ and $\mathrm{SD}=1.80 \mathrm{~ms}$, and Sedentary female mean $=21.70 \mathrm{~ms}$ and $\mathrm{SD}=0.98 \mathrm{~ms}$ with $\mathrm{t}_{(0.05)}(38)=-3.382$ and $\mathrm{p}=0.002$ is statistically significant as tabulated value of $\mathrm{t}$ $(0.05)(38)=2.024 \& \mathrm{p} \leq 0.05$.

Table: 3 of Paired Sample t-test of simple choice auditory reaction time between preferred and non-preferred hand of sports and sedentary female shows that preferred hand mean $=19.35 \mathrm{~ms}$ and $\mathrm{SD}=2.167 \mathrm{~ms}$, and non-preferred hand mean $=20.35 \mathrm{~ms}$ and $\mathrm{SD}=1.616 \mathrm{~ms}, \mathrm{t}_{(0.05)}(39)=-5.639$ and $\mathrm{p}=0.00$. It is statistically significant as tabulated value of $t_{(0.05)}(39)=2.023 \& p \leq 0.05$.

\section{Discussion}

Sports female students have exhibited their excellence in both the cases preferred and non-preferred hands in simple choice auditory reaction time over sedentary female students. Nature of the sports activity exposes athletes to react with the simple choice auditory reaction time after time in the playing field, maybe because of that reason sports female students exposed their dominance in it. This finding is partially consonance with the study of Chandra [7] confirms that at rest difference in reaction time is insignificant in preferred and non-preferred hands but it is significant while exercise was performed at elevated temperatures. Long term exercising male adults' reaction time is better than the sedentary male adults [14].

In the auditory simple choice reaction time, preferred hand's reaction time is better than non-preferred hand's reaction time in the university female students. The reason may be of being such difference that simple choice reaction time plays a great role in daily-to-day life as well as in sports, further, our instinct drives us to use our preferred hand more than non-preferred hand. Thus, the preferred hand is better trained with this stimulus than the non-preferred hand. On the preferred and non-preferred hands, the effects of warning and location of limbs are not the same [15]. Dane \& Erzurumluoglu reported that between male and female young handball players, there is no difference in left-handed players in visual reaction time but it exists in the right-handed players with male players' dominance [16].

\section{Conclusion}

University sports female students are faster than sedentary female students in terms of the simple choice auditory reaction time of preferred and non-preferred hands. University female students' preferred hand is faster in simple choice auditory reaction time than that of non-preferred hand.

\section{References}

[1] Definition of reaction time | Dictionary.com, Www.dictionary.com. (n.d.) https://www.dictionary.com/browse/reaction-time (accessed September 10, 2019).

[2] Collins, Reaction time definition and meaning | Collins English Dictionary, (n.d.). https://www.collinsdictionary.com/dictionary/english/reactiontime (accessed September 10, 2019).

[3] I. J. Deary, D. Liewald, J. Nissan, A free, easy-to-use, computer-based simple and four-choice reaction time programme: The Deary-Liewald reaction time task, Behav. Res. Methods. $43 \quad$ (2011) 258-268. https://doi.org/10.3758/s13428-010-0024-1.

[4] M. Kennefick, A. D. Wright, J. D. Smirl, P. van Donkelaar, Anticipatory postural adjustments as a function of response complexity in simple reaction time tasks, Neurosci. Lett. 684 (2018) 1-5. https://doi.org/10.1016/j.neulet.2018.06.058. 
[5] D. Maslovat, S. T. Klapp, C. J. Forgaard, R. Chua, I. M. Franks, The effect of response complexity on simple reaction time occurs even with a highly predictable imperative stimulus, Neurosci. Lett. 704 (2019) 62-66. https://doi.org/10.1016/j.neulet.2019.03.056.

[6] Madanmohan, A. B. Bhavanani, G. Dayanidy, Z. Sanjay, I. V. Basavaraddi, Effect of yoga therapy on reaction time, biochemical parameters and wellness score of peri and postmenopausal diabetic patients, Int. J. Yoga. 5 (2012) 10-15. https://doi.org/10.4103/0973-6131.91696.

[7] A. M. Chandra, S. Ghosh, S. Barman, R. Iqbal, N. Sadhu, Effect of Exercise and Heat-Load on Simple Reaction Time of University Students, Int. J. Occup. Saf. Ergon. 16 (2010) $497-$ 505. https://doi.org/10.1080/10803548.2010.11076862.

[8] M. T. G. Pain, A. Hibbs, Sprint starts and the minimum auditory reaction time, J. Sports Sci. 25 (2007) 79-86. https://doi.org/10.1080/02640410600718004.

[9] S. Jose, P. K. Gideon, Comparison between Auditory and Visual Simple Reaction Times, Neurosci. Med. (2010). https://doi.org/doi:10.4236/nm.2010.11004.

[10] Z. Pancar, M. Özdal, S. Pancar, M. Biçer, INVESTIGATION OF VISUAL AND AUDITORY SIMPLE REACTION TIME OF 11-18 AGED YOUTH, Eur. J. Phys. Educ. Sport Sci. 0 (2016). https://www.oapub.org/edu/index.php/ejep/article/view/313 (accessed September 10, 2019).

[11] D. L. Woods, J. M. Wyma, E. W. Yund, T. J. Herron, B. Reed, Factors influencing the latency of simple reaction time, Front. Hum. Neurosci. https://doi.org/10.3389/fnhum.2015.00131.
[12] M. GARG, H. LATA, L. WALIA, O. GOYAL, EFFECTOFAEROBICEXERCISEONAUDITORYANDVISU ALREACTIONTIMES: APROSPECTIVESTUDY, Indian J Physiol Pharmacol. (2013). https://pdfs.semanticscholar.org/809e/02b8929c56dc82e00bbe 71f366165723be60.pdf.

[13] M. Debeljak, G. Vidmar, K. Oberstar, A. Zupan, Simple and choice reaction times of healthy adults and patients after stroke during simulated driving, Int. J. Rehabil. Res. (2019) 280. https://doi.org/10.1097/MRR.0000000000000351.

[14] Z. ARI, N. KUTLU, B. S. UYANIK, F. TANELI, G. BUYUKYAZI, T. TAVLI, SERUM TESTOSTERONE, GROWTH HORMONE, AND INSULIN-LIKE GROWTH FACTOR-1 LEVELS, MENTAL REACTION TIME, AND MAXIMAL AEROBIC EXERCISE IN SEDENTARY AND LONG-TERM PHYSICALLY TRAINED ELDERLY MALES: International Journal of Neuroscience: Vol 114, No 5, Int. J. Neurosci. $114 \quad$ (2004). https://doi.org/10.1080/00207450490430499.

[15] R. Nakamura, R. Taniguchi, Y. Oshima, Preferred Hand and Steadiness of Reaction Time, Percept. Mot. Skills. 42 (1976) 983-988. https://doi.org/10.2466/pms.1976.42.3.983.

[16] S. DANE, A. ERZURUMLUOGLU, SEX AND HANDEDNESS DIFFERENCES IN EYE-HAND VISUAL REACTION TIMES IN HANDBALL PLAYERS, Int. J. Neurosci. 113 (2009). https://doi.org/10.1080/00207450390220367. 